Collection: RegioResources21 - "Spatial information and participation of socio-ecological systems: experiences, tools and lessons learned for land-use planning"

Guest Editors: Daniele La Rosa, Carsten Lorz, Hannes Jochen König, Christine Fürst

\section{Spatial information and participation in socio-ecological systems: experiences, tools and lessons learned for land-use planning}

\author{
Daniele La Rosa ${ }^{(1)}$, Carsten Lorz ${ }^{(2)}$, Hannes Jochen König ${ }^{(3)}$, Christine \\ Fürst ${ }^{(4)}$
}

The special issue "Spatial Information and participation of socio-ecological systems: experiences, tools and lessons learned for land-use planning", focuses on a framework for information used in planning and participation processes for socio-ecological systems at different scales and contexts. The papers presented in the SI focus on three major questions: (1) How should we make use of spatial information for planning at different scales and contexts? (2) How should we share information among stakeholders and decision makers in landuse planning? (3) How can we communicate scientific knowledge to achieve effective decisions? The papers of this SI contribute original perspectives on how spatial information can be structured, used and communicated by/among different actors of land planning processes, creating more actionable scientific knowledge and effective related decision making.

Keywords: Participation, Land-use Planning, Stakeholders, Decision-making
The role of information and participation in land-use planning

The role of information in planning processes

In general, all planning processes require the efficient integration of information, participation and management phases along their entire life-cycles to be sustainable, i.e., long lasting and well accepted. In particular, land-use planning processes focus on the design and organization of urban and non-urban physical and socio-economic spaces and the measures/actions that can be undertaken to solve or prevent problems in land use. The general objective is usually to provide decisions about activities in a certain spatial unit, which should be better than the existing pattern without planning (Hall 1975). This objective is usually achieved by using knowledge and creativity to design, evaluate and implement a set of justified actions in the public domain (Friedman 1987). The knowledge may consist of scientific and experiential knowledge, implicit and explicit knowledge, or technical knowledge and social knowledge by societal actors.

Scientific knowledge in a landscape context is frequently organized and structured as spatial information. For this type of knowledge, technology developers have long focused on supporting planners in handling and managing considerable amounts of information. However, there is not a general consensus about spatial models and technologies (particularly Geographic Information Systems) for supporting planning and decision-making processes (Fürst et al. 2010a,
(1) Department of Architecture, University of Catania (Italy); (2) Forest Pedology, Geology and Site Ecology, University of Applied Sciences Weihenstephan-Triesdorf, Woods and Forestry (Germany); (3) Leibniz Centre for Agricultural Landscape Research - ZALF (Germany); (4) Center for Development Research - ZEF, University of Bonn (Germany)

@ Carsten Lorz (carsten.lorz@hswt.de)

Received: Mar 12, 2014 - Accepted: Mar 12, 2014

Citation: La Rosa D, Lorz C, König HJ, Fürst C, 2014. Spatial information and participation in socio-ecological systems: experiences, tools and lessons learned for land-use planning. iForest 7: 349-352 [online 2014-05-19] URL: http://www.sisef.it/iforest/contents/? id=ifor0093-007

Communicated by: Marco Borghetti 2010b). This is partly related to the fact that most planning theories are based on different assumptions regarding rationality. Two types of rationality are of particular relevance for understanding the role of information in planning: (1) instrumental (or functional) rationality; and (2) communicative (or procedural) rationality (Malczewski 2004). Although the two perspectives are often viewed as antinomic, the role of information is relevant to both of them. Rather, their differences lie in the way in which the data are processed to obtain information and the way this information is used and communicated.

All planning processes should seek to produce policies and decisions that are "evidence-informed" (Davoudi 2006). However, this evidence is only one parameter among several inputs in the policy-making process. As a consequence, the socio-political context of policy processes gains in importance. Which spatial information is useful/necessary and how and by whom it might be used or elaborated (Dühr \& Müller 2012) depends on the socio-political context.

\section{Participation and information}

Land-use planning is thus more than a technical procedure because it also involves participatory approaches (Innes 1996). The last few decades have seen increasing attempts to foster "collaborative" and "participatory" approaches to spatial planning and decision making, with a more sophisticated conceptualization of the contested term "participation" (Tress \& Tress 2003). Planners must address different stakeholders, power relationships among different interest groups, and complex urban and regional interrelations/interdependencies and problems always needing considerable amounts of spatial information for their activities. This has important socio-political consequences on the use of new techniques (i.e., Participatory GIS) as tools for planning. Participatory, "bottom-up" geo-information technologies have been concurrently developing (Koschke et al. 2014), and are expected to strengthen participatory spatial planning; important among these has been the transformation of conventional mapping and GIS tools into Participatory GIS (PGIS - Jankowski \& Nyerges 2001, Fürst et al. 2010b, 2012, 2013, Gebel et al. 2012, Lorz et al. 2013, Koschke et al. 2014).

Determining how spatial information can be included in planning processes is a crucial step for achieving effective and durable results and for making decisions that are widely accepted by the involved stakeholders. A crucial objective of participatory approaches is the exchange of information among stakeholders (Joerim et al. 2009, König et al. 2013), and recent studies have defined some criteria that participatory me- 
thods handling spatial information should meet (McCall \& Dunn 2012, Carver et al. 2001). These criteria include the inclusion of social and local spatial knowledge in PGIS, the consideration of equity in stakeholders representative competency, the feasibility of the used methods, transparency in data handling and processing, and the accessibility of the achieved results (McCall 2003, McCal \& Dunn 2012). If it is not possible to meet all the aforementioned criteria, the particular planning process under examination, the local conditions and the numbers and types of stakeholders will be discriminating factors for the choice of one criterion over another With this special issue, we aim to provide new insights into selected studies that address the potential and challenges of stakeholder participation and spatial planning in trans-disciplinary land use science under different contexts. The papers in this issue seek to provide reflections and to illuminate the roles played by spatial information and stakeholder participation in land-use planning processes for socio-ecological systems, providing examples of operational methods and approaches that have been tested and applied in integrated land-use planning in different contexts with regards to scale, applications and geographical areas. Some of the papers were presented at the " 2 nd $R$ RegioResources 21" conference, held in May 2012 in Dresden (Germany). RegioResources21 conferences have been organized each year since 2001 by the European Land-Use Institute and have established a permanent cross-disciplinary dialogue on the sustainable provision of natural resources at regional and urban scales.

\section{Structure and content of the Issue}

The papers published in this Collection address three major thematic blocks: (1) the use of spatial information; (2) the transfer of information among stakeholders; and (3) the communication of scientific knowledge and decisions.

\section{Use of spatial information}

The first block addresses how spatial information might be used to support planning processes and decisions on various scales and in different contexts. The paper by Petzold et al. (2014) addresses short rotation coppice (SRC) plantations as part of green energy concept in Saxony, Germany and emphasizes the need to implement ecosystem services provided by SRC in land-use planning. The study addresses the considerable biomass potential of SRC and the related synergy effects for soil protection and nature conservation. The authors see a further need to focus on local to regional scales by considering stakeholder knowledge and to include other ecosystem services related to soil and water issues. The contribution by Gebel et al. (2014) addresses the simulation and visualization of the effects of land management and climatic frame conditions on water supplies in the Miyun catchment, China. The study addresses the generation of primary data from monitoring sites and the use of a Web-GIS modeling tool. This approach helps to understand and represent the actual processes in the Miyun catchment as well as to visualize the effects of land-use on water resources and thus provides a base for planning decisions. Zhen et al. (2014) focus on the contributions of future land-use to food security scenarios in the Guyuan district, China. The study predicts land-use changes and their potential impacts on regional food security under the influence of a land conversion program to convert agricultural land to conservation uses. By developing different scenarios, various driving forces were identified, and a "dynamics of land systems" model was used to simulate changes in land use based on the driving mechanisms. The authors emphasize the need for future landuse decisions to carefully consider the balance between land resource conservation, agricultural production, and urban expansion. The paper by Martinico et al. (2014) focuses on the importance of urban green spaces for the provision of ecosystem services. The authors develop a strategy for Green Oriented Urban Development (GOUD) that has been applied for the Master Plan of Catania, Italy. The strategy includes a limited amount of developments as well as new green spaces in selected areas of the municipality through the transfer of property and development rights between the municipality and developers. This approach to urban development will enhance the provision of ecosystem services, especially cultural services, regulating services and provisioning services, such as urban agricultural products at reduced cost for the municipal administration.

\section{Transfer of information among stakeholders}

A major problem in planning is to share information among trans-disciplinary groups of stakeholders and decision makers evenly in order to achieve an adequate level/common understanding of knowledge. The paper by Spyra (2014) reports results from a study of the land-use strategies of three Czech-Polish Euro regions. The results of this study show that land-use strategies should reflect such aspects as the further development of the cross-border region and should include a combination of economic and environmental issues. The author indicates that there are several threats to the implementation of land-use strategies, such as a lack of enthusiasm among Euroregion members, the limitations of the 2014-2020 budget of the European Union and difficulties in achieving a mutual Czech-Polish goal. In a study from
Inner Mongolia, König et al. (2014) looked at the acceptance and reflection of research topics on multifunctional land-use by local stakeholders. The most important land-use functions and services from a local stakeholder perspective were identified during a local workshop and compared to land-related research topics addressed in the scientific literature analyzed in an empirical study. The principal outcome is that stakeholders are mainly interested in social land-use functions, such as the provision of work, as well as environmental land-use functions and the maintenance of key ecosystem processes. In contrast, the research topics addressed in the scientific literature were primarily concerned with biophysical research issues (e.g., water and soil). Future research that can contribute to local policy making with the aim of meeting the objectives of a multifunctional landuse concept is urgently needed. Public participation as part of sustainable forestry is investigated by Sarvašová et al. (2014) in Slovakia. The purpose of their paper is to evaluate participatory approaches in the formulation processes of forest strategic documents and forest management plans in Slovakia. The empirical findings from forest authorities' data show that participation is still very formal. The most common actors are public authorities represented by their official representatives, and the most active actors besides forest owners or managers are environmental interest groups. To strengthen the participatory process in sustainable forestry planning, not only changes in legislation are needed but also an increase in public awareness concerning the significance of forestry resources.

\section{Communication of scientific knowledge and decisions}

The final topic is the communication of scientific knowledge and decisions about land-use planning to stakeholders. Boll et al. (2014) use the example of the introduction of dendromass use in the Hamburg Metropolitan Region, Germany and the reaction of dwellers to potential landscape changes in recreation areas. In the context of the production of biofuels, the question concerns how people perceive landscape changes and if those perceptions are influenced by the landscape itself. A survey of urban residents in the city of Hamburg showed that people rated changes significantly differently depending on the specific landscape type of the recreation areas. The authors recommend that the landscape character and the cultivation system be considered in the assessment and determination of potential short rotation coppice production sites. This may considerably increase the acceptability of dendromass cultivation for energy purposes. Warren-Kretzschmar \& von Haaren (2014) analyze the communication of planning deci- 
sions using a landscape visualization approach to support participatory environmental planning at different spatial scales and decision levels from the international to the farm level. How visualization can support participation in the planning process at the municipal level is examined in this paper by drawing on the findings of the Interactive Landscape Plan (IALP) Koenigslutter, Germany regarding the preferences and reactions of citizens to visualizations used in the landscape planning process at the local decision level. The general findings at the municipal level show that visualization can improve participation by providing participants with a common image of the planning proposals for discussion and collaborative decision making. Visualization techniques might enable farmers to understand the impacts of land-use changes at the landscape scale.

\section{Reflecting on needs for integrated tools and actionable results}

A relevant challenge in planning processes is to make decisions on land-use by policy makers more effective and actionable. This issue partially concerns the way decisions have been communicated and the extent to which stakeholders have been involved. Palmer (2012) argues that the communication of scientific knowledge is not sufficient to produce actionable outcomes because this knowledge might not be what is needed or not be in a form that is usable by policy makers.

However, fostering interdisciplinary collaborations between natural scientists from different fields or structuring studies with the goal of solving defined socio-environmental problems instead of studying the processes that cause them might not be sufficient. Each geographical context is irreducible and peculiar and has its own social, ecological and political environment; this makes it very challenging, if not unrealistic or even utopian, to provide worldwide indications for achieving more actionable results in planning processes. However, some suggestions can be summarized from the papers of this special issue for different planning sectors: the diverse nature of the papers provides original perspectives on how geo-information can be structured, used and communicated by/among different actors for land planning processes, creating more actionable scientific knowledge and related effective decision making.

In this issue, we propose a framework that consists of three main sections: (1) the use of spatial information; (2) the exchange of information among stakeholders; and (3) the communication of scientific findings to decision makers.

The use of spatial data and qualitative information can be used to visualize planning processes at different spatial scales, which helps to reveal the potential impacts of policy measures and to support the effective implementation of land use strategies (Petzold et al. 2014, Gebel et al. 2014, Zhen et al. 2014, Martinico et al. 2014).

Involving stakeholders in planning processes requires participatory and transdisciplinary methods that build a common ground of understanding while considering local perceptions and implicit knowledge to ensure an effective and accepted outcome from the planning process (Spyra 2014, König et al. 2014, Sarvašová et al. 2014).

The use of scientific knowledge in support of evidence-based decisions requires adequate techniques to bring together the stakeholder-science-policy interface, for which a clear understanding of stakeholder perceptions and the actionable communication of key findings using, for example, visualization techniques, is advantageous (see Boll et al. 2014, Warren-Kretzschmar \& von Haaren 2014).

We conclude that effective land-use planning should consider participatory and stakeholder based methods that capture local perceptions and should make use of analytical methods and visualization techniques for communicating key findings along the stakeholder-science-policy interface. Ultimately, there will be no single method or approach that addresses all the interdependencies of a complex socio-ecological system.

\section{Acknowledgements}

The guest editors would like to thanks all authors for their commitment in the Special Issue making and their relevant scientific contributes. Special thanks go to the all the reviewers who have done great work in assisting the editors' work and helped the authors with significant suggestions to improve their manuscripts.

\section{References}

Boll T, von Haaren C, Albert C (2014). How do urban dwellers react to potential landscape changes in recreation areas? - a case study with particular focus on the introduction of dendromass in the Hamburg Metropolitan Region. iForest 7: 423-433. - doi: 10.3832/ifor1173-007

Carver S, Evans A, Kingston R, Turton I (2001). Public participation, GIS, and cyber-democracy: evaluating on-line spatial decision support systems. Environment and Planning B: Planning and Design 28: 907-921. - doi: 10.1068/b2751t

Davoudi S (2006). Evidence-based planning. Rhetoric and reality. disP - The Planning Review 165: 14-24. - doi: 10.1080/02513625.2006.1055 6951

Dühr S, Müller A (2012). The role of spatial data and spatial information in strategic spatial planning. Regional Studies 46: 423-428. - doi: 10.1080/00343404.2012.669535

Fürst C, König H, Pietzsch K, Ende HP, Makeschin F (2010a). Pimp your landscape - a generic approach for integrating regional stakeholder needs into land use scenario design and sustainable management support. Ecology and Society 15 (3): 34-59.

Fürst C, Volk M, Makeschin F (2010b). Squaring the circle - how to combine models, indicators, experts and end-users for integrated land use management support? Environmental Management 46 (6): 829-833. - doi: 10.1007/s00267010-9574-3

Fürst C, Pietzsch K, Witt A, Frank S, Koschke L, Makeschin F (2012). How to better consider sectoral planning information in regional planning: example afforestation and forest conversion. Journal of Environmental Planning and Management 55 (7): 855-883. - doi: 10.1080/09640568. 2011.630067

Fürst C, Frank S, Witt A, Koschke L, Makeschin F (2013). Assessment of the effects of forest land use strategies on the provision of ecosystem services at regional scale. Journal of Environmental Management 127: S96-S116. - doi: 10.1016/j.jenvman.2012.09.020

McCall MK (2003). Seeking good governance in participatory-GIS: a review of processes and governance dimensions in applying planning. Habitat International 27: 549-573. - doi: 10.1016 /S0197-3975(03)00005-5

McCall MK, Dunn CE (2012). Geo-information tools for participatory spatial planning: Fulfilling the criteria for "good" governance? Geoforum 43: 81-94. - doi: 10.1016/j.geoforum.2011.07.0 07

Friedman J (1987). Planning in the public domain: from knowledge to action. Princeton University Press, Princeton, NJ, USA, pp. 501.

Gebel M, Halbfaß S, Bürger S, Lorz C (2012). Effects of energy crop cultivation on nitrogen leaching and surface water quality in Saxony/Germany. Regional Environmental Change 13: 249-261 - doi: 10.1007/s10113-012-0330-5 Gebel M, Meißner R, Halbfass S, Hagenau J, Duan S (2014). WebGIS based simulation of water and nutrient fluxes in the Miyun catchment area. iForest 7: 363-371. - doi: 10.3832/ifor11 69-007

Hall P (1975). Urban and regional planning. Penguin Books, Harmondsworth, UK, pp. 312. Innes JE (1996). Planning through consensus building: a new view of the comprehensive planning ideal. Journal of the American Planning Association 62: 460-472. - doi: 10.1080/01944369 608975712

Jankowski P, Nyerges T (2001). Geographic information systems for group decision making-towards a participatory, geographic information science. Taylor \& Francis, New York, USA, pp. 273

Joerim F, Desthieux G, Billeau Beuze S, Nembrini A (2009). Participatory diagnosis in urban planning: Proposal for a learning process based on geographical information. Journal of Environmental Management 90: 2002-2011. - doi: 10.1016/j.jenvman.2007.08.024

König HJ, Uthes S, Schuler J, Zhen L, Purushothaman S, Suarma U, Sghaier M, Makokha 
S, Helming K, Sieber S, Chen L, Brouwer F, Morris J, Wiggering H (2013). Regional impact assessment of land use scenarios in developing countries using the FoPIA approach: Findings from five case studies. Journal of Environmental Management 127 (suppl): S56-S56. - doi: 10.10 16/j.jenvman.2012.10.021

König HJ, Podhora A, Helming K, Zhen L, Wang C, Wübbeke J, Baumeister T, Du B, Yan H (2014). Confronting international research topics with local stakeholder perspectives on multifunctional land use: the case of Inner Mongolia, China. iForest 7: 403-413. - doi: 10.3832 ifor 1172-007

Koschke L, Lorz C, Fürst C, Lehmann T, Makeschin F (2014). Assessing hydrological and provisioning ecosystem services in a case study in Western Central Brazil. Ecological Processes 3: 2. - doi: 10.1186/2192-1709-3-2

Lorz C, Neumann C, Bakker F, Pietzsch K, Weiss H, Makeschin F (2013). A web-based planning support tool for sediment management in a meso-scale river basin in Western Central Brazil. Journal of Environmental Management 127: S15-S23.

Malczewski J (2004). GIS-based land-use suitability analysis: a critical overview. Progress in Planning 62: 3-65. - doi: 10.1016/j.progress.20 03.09.002

Martinico F, La Rosa D, Privitera R (2014). Green Oriented Urban Development for urban ecosystem services provision in a medium sized city in southern Italy. iForest 7: 385-395. - doi: 10.38 32/ifor1171-007

Palmer MA (2012). Socioenvironmental sustainability and actionable science. BioScience 62 : 5-6 - doi: 10.1525/bio.2012.62.1.2

Petzold R, Butler-Manning D, Feldwisch N, Glaser T, Schmidt P A, Denner M, Feger K-H (2014). Linking biomass production in short rotation coppice with soil protection and nature conservation. iForest 7: 353-362. - doi: 10.3832/ ifor1168-007

Sarvašová Z, Dobšinská Z, Šálka J (2014). Public participation in sustainable forestry: the case of Slovakia. iForest 7: 414-422. - doi: 10.3832/ ifor1174-007

Spyra M (2014). The feasibility of implementing cross-border land-use strategies: A report from three Upper Silesian Euroregions. iForest 396402. - doi: 10.3832/ifor 1248-007

Tress B, Tress G (2003). Scenario visualisation for participatory landscape planning - a study from Denmark. Landscape and Urban Planning 64: 161-178. - doi: 10.1016/S0169-2046(02)002 19-0

Warren-Kretzschmar B, von Haaren C (2014). Communicating spatial planning decisions at the landscape and farm level with landscape visualization. iForest 7: 434-442. - doi: 10.3832/ifor 1175-007

Zhen L, Deng X, Wei Y, Jiang O, Lin Y, Helming K, Wang C, König HJ (2014). Future land use and food security scenarios for the Guyuan district of remote western China. iForest 7: 372384. - doi: 10.3832/ifor1170-007 